\title{
Por una Escuela Inclusiva. Las Fronteras del Género
}

\author{
For an Inclusive School. The Gender Frontiers
}

Paloma Curieses *

Universidad Autónoma de Madrid

\begin{abstract}
Una de las metas que se plantean quienes abogan por la igualdad social en el sistema educativo es la escuela inclusiva. Reconocido el derecho a la educación de todas las personas, siguen siendo numerosas las voces que reclaman la necesidad de pensar, estudiar, proponer y comprometerse con nuevas formas de entender y enfocar la educación de la diversidad del alumnado. Así, surge la idea de una escuela inclusiva. Esta corriente tiene como objetivo ir más allá de la idea de integración, imperante en la legislación española, implicando una reestructuración de las escuelas para lograr responder a las necesidades de todo el alumnado. Es importante reparar en que la necesidad de identidad, y por extensión de representación -política-, se entiende como una necesidad básica y que debe tener, por tanto, su consideración en el ámbito educativo, con objeto de evitar cualquier forma de segregación dentro del aula. Defiendo la necesidad de atender, igualmente, a las diferentes formas de ser, de definirnos e identificarnos, como parte esencial de estas diversidades. A través del análisis de la paradoja de la identidad femenina, las fronteras del género y sus consecuencias sobre la agencia en el seno del feminismo, propongo una ampliación del concepto de educación inclusiva con el objetivo de dar un paso más a la hora de hablar de una educación realmente equitativa, crítica y democrática.
\end{abstract}

Descriptores: Diversidad cultural, Escuela, Frontera, Derecho, Justicia social.

One of the goals of those who advocate social equality in the education system is inclusive schooling. Recognized the right to education of all people, there are still many voices who claim the need to think, study, propose and commit to new ways of understanding and focus the education of the diversity of students. Thus, the idea of an inclusive school arises. These current aims to go beyond the idea of integration, prevailing in Spanish legislation, involving a restructuring of schools to meet the needs of all students. It is important to note that the need for identity, and by extension of representation - policy-, is understood as a basic necessity and should therefore have its consideration in the educational field, in order to avoid any form of segregation within the classroom. I defend the need to attend equally to the different ways of being, to define and identify ourselves, as an essential part of these diversities. Through the analysis of the paradox of feminine identity, gender boundaries and their consequences on the agency within feminism, I propose an extension of the concept of inclusive education with the objective of taking a step further in speaking about a truly equitable, critical and democratic education.

Keywords: Cultural diversity, School, Boundaries, Law, Social justice.

*Contacto: palomacurieses@gmail.com

ISSN: 2254-3139

www.rinace.net/riejs/

revistas.uam.es/riejs
Recibido: $\quad 5$ de abril 2017

$1^{\text {a }}$ Evaluación: 15 de julio 2017

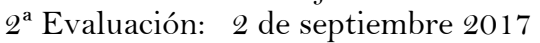

Aceptado: $\quad 16$ de septiembre 2017 


\section{Introducción}

La educación es una preocupación permanente de todos los gobiernos y Organismos Internacionales, no sólo por razones de responsabilidad para con la ciudadanía, sino también por criterios ideológicos y de organización social. En España se han producido numerosos avances educativos en las últimas décadas, aportando un enriquecimiento conceptual, sobre todo en lo que refiere a la consideración del alumnado con necesidades especiales -consagrado por la LOGSE (1990)- y a los planteamientos de atención a la diversidad, incorporando nuevas ideas de participación y aceptación de diferentes valores y formas de ser.

Con motivo de atender a esta diversidad en las aulas, considero que es igualmente necesario reflexionar sobre los últimos planteamientos de ciertas teorías enmarcadas en el feminismo posmoderno acerca de la identidad de género. Con el fin de alcanzar la igualdad social, no sólo es importante atender al alumnado con necesidades específicas de apoyo educativo (Ley Orgánica de Educación, 2006) o a las desigualdades personales, culturales, económicas y sociales, con especial atención a las que se derivan de cualquier tipo de discapacidad -o diversidad funcional- (Ley Orgánica para la Mejora de la Calidad Educativa, 8/2013), sino que también se ha de atender a la pluralidad y las diferencias que se resisten a quedar atrapadas bajo el paraguas de conceptos como mujeres o varones, es decir, que se resisten a dejarse sobredeterminar, entendiendo que únicamente de ese modo se garantiza el desarrollo de todos y todas, se favorece la equidad y se contribuye a una mayor cohesión social.

Si bien es reconocido el derecho a la educación de todas las personas, siguen siendo numerosas las voces que reclaman la necesidad de pensar, estudiar, proponer y comprometerse con nuevas formas de entender y enfocar la educación de la diversidad del alumnado. Así, surge la idea de una escuela inclusiva ${ }^{1}$. Esta corriente tiene como objetivo ir más allá de la idea de integración, imperante en la legislación española, implicando una reestructuración de las escuelas para lograr responder a las necesidades de todo el alumnado² (Martínez-Abellán, de Haro y Escarbajal, 2010). A este respecto, opino que es importante reparar en que la necesidad de identidad, y por extensión de representación -política-, se entiende como una necesidad básica (Galtung, 2003) y que debe tener, por tanto, su consideración en el ámbito educativo, con objeto de evitar cualquier forma de segregación dentro del aula.

\footnotetext{
1 Movimiento surgido a partir de la Conferencia Mundial de Educación para Todos, celebrada en 1990 en Jomtien (Tailandia). "En 1990, los delegados de 155 países, y los representantes de 150 organizaciones gubernamentales y non gubernamentales, acordaron en la Conferencia Mundial sobre la Educación para Todos en Jomtien, (Tailandia) (5-9 de marzo de 1990), hacer que la enseñanza primaria fuera accesible a todos los niños y reducir masivamente el analfabetismo antes de finales del decenio [...] en la que se reafirma que la educación es un derecho humano fundamental, y se insta a los países a que realizaran mayores esfuerzos para atender las necesidades básicas de aprendizaje de todos" (UNESCO, 1990)

2 La integración educativa es una estrategia orientada a que el alumnado con necesidades educativas especiales se incorporen a la educación ordinaria con los apoyos necesarios, mientras que la inclusión educativa implica que todos los niños y niñas de una determinada comunidad aprendan conjuntamente, independientemente de sus condiciones personales, sus hándicaps, su origen o su problemática. "El informe Warnock distingue tres formas de integración (Aguilar Montero, 1991): La integración física o local que existe cuando las clases especiales se encuentran en escuelas ordinarias, compartiendo el mismo entorno físico, pero su funcionamiento y organización es totalmente independiente; La integración social, que se da cuando los niños asisten a clases especiales dentro de un centro ordinario, pero participan con los demás en actividades extracurriculares; La integración funcional, que se consigue cuando los niños con necesidades educativas especiales y sus compañeros participan conjuntamente, a tiempo parcial o completo, en los programas educativos y en aulas ordinarias" (Araque y Barrio, 2010, pp. 9-10).
} 


\section{El género en el sistema educativo}

A la hora de abordar cualquier cuestión relacionada con la idea de género, se hace necesario comenzar analizando a qué refiere comúnmente dicha categoría. El concepto de género nació en la década de los años 60 de la mano de dos norteamericanos: John Mooney, el cual propuso el término gender roles para referirse a las conductas sociales atribuidas a los hombres y a las mujeres en la cultura, y Robert Stoller (citado por Castellanos, 2006) es médico psicoanalista y afirmó que la identidad de género es un desarrollo personal a partir de una diferencia biológica. Este concepto de género pasó a ser usado por el feminismo como una categoría de análisis relacional que permitía estudiar el sistema de relaciones sociales, simbólicas y psíquicas, la construcción de la masculinidad y la feminidad en base a una serie de diferencias biológicas. Además, permitía desvelar dicho sistema de relaciones sociales como desigual, puesto que las mujeres aparecían en una situación desfavorable con respecto a los hombres.

Los conceptos de sexo y de género pasaron a ser entendidos como aquello que

$$
\begin{aligned}
& \text { se refiere a las diferencias innatas y biológicamente determinadas entre hombres y } \\
& \text { mujeres que son universales y relativamente invariables, transpersonal y } \\
& \text { transculturalmente; y, por su parte, el término género pasó a ser usado para describir } \\
& \text { aquellas características de mujeres y hombres que son socialmente construidas. } \\
& \text { (Bosch, Ferrer y Alzamor, 2006, p. 87) }
\end{aligned}
$$

El género se constituyó como la categoría explicativa de la construcción social simbólica histórico-cultural de los hombres y las mujeres sobre la base de la diferencia sexual. Se trata de una definición del género en la que se halla implícita la idea de que hay un tipo de relación entre ambos sexos que se produce en base al poder que ejerce uno sobre el otro, a saber: el sexo masculino sobre el femenino, recogida en la idea de patriarcado, el cual es definido por Marcela Lagarde como "un orden social genérico de poder, basado en un modo de dominación cuyo paradigma es el hombre" (Bosch, Ferrer y Alzamor, 2006, p. 27). Sin embargo, es importante señalar que, más adelante, fue puesta en duda igualmente esta idea de sexo, porque

$$
\begin{aligned}
& \text { si se refuta el carácter invariable del sexo, quizás esta construcción denominada } \\
& \text { «sexo» este tan culturalmente construida como el género; de hecho, quizá siempre fue } \\
& \text { género, con el resultado de que la distinción entre sexo y género no existe como tal. } \\
& \text { (Butler, } 2007, \text { p. } 55)^{3}
\end{aligned}
$$

Siguiendo las líneas de los estudios feministas, y gracias a la aplicación de una perspectiva de género, investigaciones llevadas a cabo sobre el campo de la educación han mostrado que existen formas de discriminación en los códigos, escenarios y protagonistas del sistema educativo, los contextos escolares y la cotidianidad, así como han advertido sobre el carácter sexista de los textos escolares, en sus contenidos e ilustraciones. Este tipo de prácticas conllevan la reproducción de todo un imaginario

\footnotetext{
${ }^{3} \mathrm{Si}$ bien la idea de género resulta útil como categoría analítica, porque permite estudiar el sistema de relaciones sociales, simbólicas y psíquicas, la construcción de la masculinidad y la feminidad en base a una serie de diferencias biológicas, así como permite desvelar dicho sistema de relaciones sociales como desigual, puesto que las mujeres aparecen en una situación desfavorable con respecto a los hombres, igualmente debía ser sometida a crítica, precisamente por su carácter normativo en tanto que se articula sobre una asimetría e implica una "heterodesignación", entendida como una construcción de la sexualidad donde el sujeto de discurso es el varón. El género, como aparato discursivo, funciona como el sociabilizador de la norma. "Las reglas del género se muestran como gran reguladora. Llegando a demostrar su poder discursivo, incluso, a la hora de atacar al propio sexismo, importante diferenciador de los géneros. El cual a través de su aparato discursivo, se auto-reduce a un mero «lo que los hombres hacen a las mujeres». Esta posición victimizada de la mujer, cumple el objetivo heteropatriarcal y sexista, no buscado por el feminismo, pues potencia la demarcación entre los géneros" (Ventura, 2016, p. 11).
} 
social que implica una educación diferencial en base al género, es decir, en base a las inscripciones mujer o varón. Lo que procura, a su vez, la reproducción de un sistema que invisibiliza, naturaliza, relega a los márgenes y, finalmente, ejerce violencia contra las personas adscritas a la categoría de mujeres. De este modo, se genera un círculo vicioso.

En nuestra sociedad es evidente que persiste la exclusión por motivos de género, debido a que es patente y manifiesta en los distintos ámbitos de desarrollo social, ciudadano, escolar e individual. De ahí, la importancia innegable del desarrollo de nuevos patrones potenciados desde el ámbito escolar, porque la coeducación es hoy no sólo un derecho sino una obligación. Por su parte, la legislación recoge consignas como la siguiente:

La equidad, que garantice la igualdad de oportunidades para el pleno desarrollo de
la personalidad a través de la educación, la inclusión educativa, la igualdad de
derechos y oportunidades que ayuden a superar cualquier discriminación y la
accesibilidad universal a la educación, y que actúe como elemento compensador de las
desigualdades personales, culturales, económicas y sociales, con especial atención a
las que se deriven de cualquier tipo de discapacidad. (Ley Orgánica de Educación,
2006, p. 14; Ley Orgánica para la Mejora de la Calidad Educativa, 8/2013, p.
9)

Pero no es posible afirmar que el sistema es coherente con sus propios principios en tanto siga existiendo una desigualdad de género a nivel simbólico, socio-cultural e institucional, reflejado todo ello en el sistema educativo. Detrás de una aparente neutralidad ideológica, se esconden toda una serie de mecanismos políticos que regulan las relaciones de poder dentro de las escuelas.

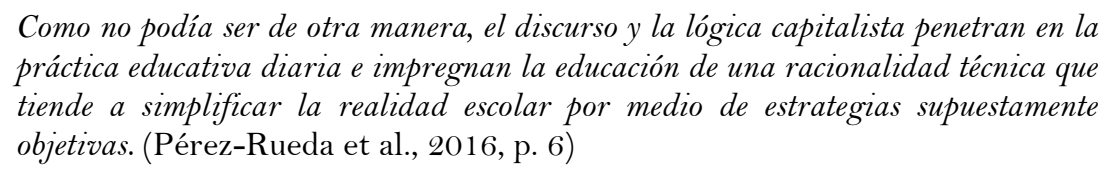

Sin plantearnos las raíces de dicha problemática de manera que nos ayude a ofrecer nuevas soluciones, no se podrá cumplir plenamente con el principio de atención a la diversidad, basado en la obligación de los Estados y sus Sistemas Educativos a garantizar a todos el derecho a la educación, reconociendo la diversidad de sus necesidades, combatiendo las desigualdades y adoptando un modelo educativo abierto y flexible que permita el acceso, la permanencia escolar de todo el alumnado, sin excepción, así como resultados escolares aceptables (UNESCO, 1994).

\section{Inclusión de la diversidad (de género)}

Es posible decir que diversas características del alumnado (estilos cognitivos, ritmos de aprendizaje, altas capacidades, discapacidad, etc.) están en relación a su situación individual, mientras que otras lo están en relación a su situación social (pertenencia a minorías étnicas o culturales, pertenencia a entornos sociales desfavorecidos, etc.). Pero ambas perspectivas se entrecruzan en tanto que no dependen únicamente del sujeto o de la sociedad, sino de ambos.

Se ha verificado un cambio en la concepción de las diferencias humanas. Se ha
pasado de una concepción de esas diferencias como manifestación de una patología
del sujeto a la asunción de un conjunto de diferencias físicas, intelectuales,
emocionales y socioculturales. (González-García, 2009, p. 435)

$\mathrm{Y}$ dentro de las diferencias humanas se halla el evidente binomio mujeres-varones, que implica la pertenencia a una clase, a un grupo, con las exclusiones e injusticias sociales 
que implica siempre la existencia de grupos diferenciados. Pero, además, dentro del propio binomio mujeres-varones hay, igualmente, toda una gama de diferencias humanas que deben tenerse en consideración en el panorama educativo. Las diferencias habituales entre los seres humanos componen una sociedad de diferentes que obliga a aprender a vivir en el respeto a esas diferencias, buscando en ellas motivos y causas de enriquecimiento para todos. Por tanto,

\begin{abstract}
la psicología y la pedagogía de hoy entienden las diferencias individuales ante el fenómeno educativo, más que como consecuencia de la capacidad general y de las aptitudes de cada estudiante, como un exponente de los diferentes modos (heterogéneos y variables, en función de factores diversos), en que los seres humanos adquieren, construyen, organizan, jerarquizan y retienen conocimientos, siempre en permanente interacción dialéctica con los ambientes de aprendizaje. De esta manera, la psicopedagogía actual ha dejado de considerar las diferencias individuales como factores estáticos, para entenderlas como realidades que son susceptibles de modificación. (Araque y Barrio, 2010, p. 11)
\end{abstract}

Y esta nueva visión psicopedagógica llega de la mano de las teorías del feminismo posmoderno, las cuales hunden sus raíces en el pensamiento de la Teoría Crítica. Siguiendo a Albrecht Wellmer (1993), es importante explicar que esta corriente de pensamiento sometió las abstracciones del pensamiento moderno a una deconstrucción, centrando sus reflexiones sobre el racionalismo -fruto del proyecto ilustrado- y su triada epistemológica sujeto, objeto y concepto. Centrándonos en la idea de sujeto, resultó que la autonomía que se le venía adjudicando al Yo (aquello que permitía ejercer su razón libremente y conducirle hacia la verdad y la justicia) se descubrió como una impotencia fáctica: la razón es exclusivamente expresión de las fuerzas y relaciones de poder psíquicas y huella de la presión de fuerzas y relaciones de poder sociales. No hay un Yo completo, que se auto-conoce y sabe lo que quiere, sino que supone el resultado de fuerzas de las cuales no es dueño, pero con las que se ve obligado a relacionarse. Y en esta relación, para no salir perdedor, lucha para ejercer el poder. La conclusión fue: desde siempre ha anidado una voluntad de poder en el interior del argumento racional y de la conciencia moral, como una fuerza ajena a la esfera inteligible.

Esta línea de reflexión llevaría a Michel Foucault (1979, 2008, 2012) a postular sus ideas acerca de la subjetividad y del saber-poder. Una concepción del poder incorporado en las prácticas y cuerpos, entendido también como biopoder. Su idea sobre el poder trajo como aspectos positivos mostrar la complejidad del poder moderno ${ }^{4}$, proporcionando las bases conceptuales y empíricas para hablar de cuestiones como la familia o el sexo, entendidas como fenómenos políticos. Así mismo, permitió articular la crítica de que abstracciones como sexo (y no sólo las de hombre/sujeto) son categorías fundamentadoras e instrumentos de dominio, en tanto que el poder moderno agrupó en una unidad artificial elementos que permitieron el funcionamiento de la sociedad moderna como causa de esa misma unidad ficticia (Foucault, 2008). Permitió vislumbrar que no es posible acceder a la verdad -o a la materia del cuerpo- sino es a través de los discursos, las prácticas y las normas. Es por ello que Judit Butler afirma que el discurso establece todo lo que es imaginable sobre el género. El discurso establece lo normativo, aquello que se considera

\footnotetext{
${ }^{4}$ Es interesante atender a la idea que sostenía Michel Foucault acerca del poder. Según explicó Guilles Deleuze, Foucault presentaba en su obra Surveiller et punir (Vigilar y castigar), publicada en el año 1975, una "caja de herramientas" que "podía explicarse como un ejercicio de suspensión metódica de los principales postulados mantenidos por los discursos tradicionales acerca del poder, [...] de tesis tópicas que guían los análisis políticos al uso y que son entendidos ahora como obstáculos que impiden un acceso fecundo a la problemática del poder contemporáneo" (Foucault, 2008, p. 9)
} 
de sentido común y que se pretende como natural, de manera que la norma rige lo ininteligible y lo que es comprensible (Ventura, 2016). Así, opina que uno de los errores principales que se ha cometido en relación a la categoría mujeres (o varones) es dar por hecho que no existe un sujeto anterior a la ley.

Los campos de «representación» lingüística y política definieron con anterioridad el criterio mediante el cual se originan los sujetos mismos [...]. El poder político "produce» irremediablemente lo que afirma sólo representar [...]. La hipótesis prevaleciente de la integridad ontológica del sujeto antes de la ley debe ser entendida como el vestigio contemporáneo de la hipótesis del estado de naturaleza. (Butler, 2007, pp. 46-48)

Foucault presentó una manera diferente de concebir y percibir las teorías acerca del yo y de la sociedad, conjugándolo con un nuevo método de evaluación. Pero su método conduce a una práctica de autorrechazo: a pensar contra nuestra propia identidad, sospechosa de estar al servicio del poder en tanto que participa del mismo, al servicio de intereses patriarcales y de ser, por extensión, opresora. La identidad y el género aparecen como algo sumamente complejo, estando en juego con el poder, lo que supone una dificultad para pensar en la resistencia al mismo. Pero, si bien el poder produce y somete, la producción que lleva a cabo el poder de los sujetos no siempre tiene el resultado esperado. Y esto es lo que va a interesar a Butler: precisamente el fracaso de los propósitos del poder. Judit Butler ofrece un punto de vista desde el que es posible desarticular el determinismo social que niega la posibilidad de que el agente actúe y cambie.

Las mujeres y varones suponen sujetos abiertos a la multiplicidad, porque pueden ser más allá de su sexo/género, tienen la capacidad de agencia de romper con la hiteración ${ }^{5}$ que consolida la herencia sociocultural, la lengua que hablamos. Judit Butler, siguiendo la senda trazada por Simone de Beauvoir (2005), considera que no puede tener sentido la idea de una construcción del sujeto en la que no pueda haber, de hecho, un constructor humano, un agente, anterior a la construcción recibida pasivamente de una ley cultural, aparentemente, inevitable. Es más, cipor qué se ha de suponer que esa construcción, que da lugar a la identidad, se mantiene intacta a través del tiempo, unificada e internamente coherente? De este modo, se hace posible entender las individualidades y las diferencias particulares como realidades susceptibles de modificación.

Esta nueva perspectiva sobre la identidad de género, que permite reconocer la pluralidad de modos de ser y las diferencias entre las personas, no sólo supone una liberación para los propios individuos, hasta ahora sujetos a categorías como mujer o varón sobre las que pesaba una idea de referente fijo la cual conlleva una normalidad que inmoviliza. También supone avanzar como sociedad, porque obliga a replantearse el hacer -tanto práctico como teórico- en la política y, por consiguiente, el hacer en el sistema educativo (no olvidemos que la educación es, también, una cuestión política, sujeta a criterios

\footnotetext{
${ }^{5}$ Podría entenderse como una iterabilidad esencial, esto es, como la capacidad de repetición-alteridad, lo cual tiene gran incidencia en la posibilidad de comunicación y de inscripción (entendida como un encontrar al otro, hablar con él en tanto otro que yo). La diferencia que se registra en el concepto de iterabilidad acopla los de repetición y alteridad -posibilidad de injertar-. Se puede decir que es repetición que se altera con cada nuevo contexto en que reaparece la "misma" marca, pues la unidad de la forma significante sólo se constituye precisamente por su iterabilidad, esto es: por la posibilidad de ser repetida en la ausencia no sólo de su referente, sino en la ausencia de un significado determinado o de la intención de significación actual, como de toda intención de comunicación presente. Que sea repetible es tanto como decir que lo que se produce es una marca productora que no requiere de la presencia de "aquella" supuesta producción ni de otro presunto "productor" que vele por su eficacia. La presencia diferida no es cuestión de salvarla por una suerte de mediación, sino que requiere de "alguien otro" (Derrida, 1998)
} 
ideológicos y de organización social). Considero que pensar(nos) de este modo favorece las pretensiones de impulsar la educación inclusiva en los centros educativos, coincidiendo con la necesidad de identificar y analizar los contextos sociopolíticos educativos favorecedores de prácticas inclusivas.

Los autores Araque y Barrio (2010) señalan, basándose en investigaciones, las siguientes claves a tener en cuenta para desarrollar una educación inclusiva:

Un contexto político abierto y participativo. Cuanto más clara y coherente sea la política educativa, más posibilidades hay de desarrollar prácticas inclusivas. Las sociedades con más trayectoria democrática y participativa poseen mayor capacidad de respuesta hacia la inclusión.

La apropiación del cambio, de su idea y significado sobre la educación inclusiva y el concepto de diversidad. Analizando la realidad del centro, estableciendo prioridades y necesidades, suprimiendo barreras que impidan la participación, reflexionando sobre el ideario del centro, sobre su presente y futuro, etc.

La participación e implicación de todos los miembros de la comunidad educativa en la gestión, planificación y desarrollo del proyecto educativo del centro. Creando y desarrollando actividades para implicar al alumnado, a los padres y a los profesionales, facilitando un clima de apertura y participación para todos, creando una visión de futuro institucional compartida, etc.

El apoyo centrado en la escuela, utilizando todos los recursos didácticos y humanos, materiales y financieros del centro, creando redes naturales de apoyo entre el profesorado, alumnado y padres, etc. Las localidades o distritos con más y mejores prácticas inclusivas emplean e invierten más recursos económicos a esta finalidad.

La colaboración entre servicios educativos. La acción conjunta en planes de actuación entre los distintos servicios (Centros Educativos, Sanidad, Ayuntamiento, etc.), en una localidad o distrito favorece el desarrollo de prácticas inclusivas educativas y sociales, así como el aprovechamiento de los recursos ordinarios. (Araque y Barrio, 2010, pp. 19-20)

De esta lista de propuestas para desarrollar una educación inclusiva, me gustaría destacar ideas como: un contexto abierto y participativo, trayectoria democrática y participativa, suprimiendo barreras que impidan la participación, implicación de todos los miembros de la comunidad educativa, creando redes naturales de apoyo o la colaboración entre servicios educativos (señalar que esta última resultaría como consecuencia de la anterior, que funcionaría como antecedente suficiente aunque no necesario). Todas estas propuestas metodológicas se ven impregnadas de las ideas que impulsan, a su vez, la teoría desarrollada por Benhabib (2004) quien, a través de la defensa de un universalismo interactivo, aboga por una democracia deliberativa basada en el discurso. Estos principios los aplica la autora, no sólo a la hora de reflexionar sobre las fronteras de una comunidad política y sobre aquello que regula la condición de miembro de un determinado territorio, sino también a la hora de examinar el problemático binarismo conceptual mujeres-varones $\mathrm{y}$ las fronteras entre ambas categorías.

\section{La paradoja de la identidad}

Para poder abordar de manera adecuada el planteamiento acerca de las fronteras entre el binarismo conceptual mujeres-varones, es necesario enunciar brevemente lo que podríamos llamar la paradoja de la identidad femenina y sus consecuencias sobre la agencia. Se trata de una de las problemáticas que más repercusiones tiene en la 
actualidad para el feminismo, y que surge con las teorías de la filosofía crítica. Grosso modo, con la intención de responder a la pregunta ¿qué es lo esencialmente femenino? (Beauvoir, 2005), se descubrió el género como una construcción sociocultural naturalizada gracias al correlato sexo-género, estableciéndose, además, una heterosexualidad normativa, pues los dispositivos socioculturales dividen a mujeres y varones en dos categorías sociales opuestas, jerárquicas e incompletas (Rubin, 1986). El género se reveló como una ficción totalizante perniciosa, lo que lleva a preguntarse: ¿realmente existe una esencia femenina (así como masculina)? Y es que, como se ha dicho anteriormente, la deconstrucción de las categorías esencialistas de la modernidad como la de sujeto-, permitió vislumbrar que el poder aúna en unidades ficticias y, así, anticipa los fenómenos que posteriormente dice legislar, entendiéndolas como una esencia interior previa a la ley. Genera una expectativa que acaba produciendo el fenómeno mismo que anticipa, reproduciéndose así: ideas, conductas, roles... en la sociedad. Una sociedad hetero-patriarcal en la que las mujeres fueron condenadas a quedar relegadas a los márgenes.

Durante la modernidad, se apuntala la idea de lo masculino, y de aquellos sujetos a esta categoría (entendidos como sujetos universales -hombre como lo neutro-, individualizados y trascendentales) generada en oposición a lo femenino y a aquellas personas sujetas a dicha categoría (entendidas como alteridad -otro nosotros-, alienación identitaria -las mujeres como un todo- e inmanencia). De este modo, se genera el problema de que el sujeto colectivo mujeres amenaza la necesidad básica de identidad y, por extensión, de representación -política-. El pensamiento de la modernidad excluyó a las mujeres de la categoría de sujeto, y de sus adheridas abstracciones: individuo y ciudadano. Pero, al mismo tiempo, abrió un nuevo paradigma de pensamiento, se elaboraron una serie de categorías que permitieron a las mujeres vehicular sus demandas: si hablamos de universalidad e igualdad, hagámoslo en serio. Fueron los ideales de la modernidad aquellos que permitieron la creación de herramientas para la vindicación de los derechos, esto es, para la lucha contra la opresión.

Aparece en el siglo XIX el término feminismo, el cual, paradójicamente, queriendo destruir las diferencias jurídicas, económicas y sociales, basadas en la percepción de diferencias biológicas entre los sexos, evocó precisamente esas diferencias para articular sus reivindicaciones. El feminismo se iba a encargar de la cuestión de la mujer, como se denominó entonces, lo cual evidencia la idea de identidad de grupo que se generó. Se apuntaló una identidad de grupo y, por lo tanto, se reforzaron las diferencias. El modelo estereotipado de lo que debe ser una mujer fue y es asumido por las propias mujeres como algo inherente a sí mismas, como su propia identidad. Ahora, el problema que se plantea es: ¿cómo conjugar que, si bien el sujeto colectivo mujeres favorece su conversión en objetos de abuso, al mismo tiempo, en la práctica se impone la necesidad de una identidad colectiva para dirigir las estrategias de lucha del feminismo?

Se trata de un problema aparentemente circular y recurrente, porque mientras que las teorías posmodernas llevan a pensar que la mujer no existe y, por tanto, tampoco las mujeres (cabe preguntarse si realmente puede existir un sujeto del feminismo, una identidad común), el feminismo precisa saber -al igual que sucede en todo colectivo y movimiento político- quién(es) habla(n) y para quién(es) habla(n). Es decir, cicómo llevar a cabo esta labor de deconstruir y desencializar sin desestimar, al mismo tiempo, al sujeto político capaz de acción, aquel que ostentaba la determinación identitaria? Así, es 
necesario preguntarse qué rasgos, características y/o vivencias se reúnen bajo el paraguas de la categoría mujeres, identidad política que sustenta y a la que se dirigen las estrategias de lucha del feminismo. Pero sucede que, al hacer esta reflexión, nos encontramos cayendo de nuevo en el problema de vernos forzadas a asumir lo que se ha impuesto tradicionalmente que debe ser una mujer, lo que da lugar a unos roles y mandatos de género en base a un sexo. Se observa que esta circularidad está atravesada, por un lado, por el problema de la agencia - política- y, por otro lado, por el problema de la identidad -política-. Y es que, no es posible atender a la pregunta de cómo actúa el sujeto sin antes haberse preguntado por el modo en cómo éste se construye. Es decir, sin pensar en la politización del sujeto no es posible pensar en el sujeto para la política, lo que implica situarnos en una politización radical del sujeto.

Pero, más allá de ver esta problemática como algo negativo para el feminismo, esta reflexión crítica ha brindado la oportunidad de entender las fronteras del género como porosas, abiertas a reformulaciones, tal como advierten Judit Butler y Seyla Benhabib entre otras/os. Aunque nos vemos empujadas a pensar en la idea de las mujeres -como colectivo-, se rechaza ahora que esta categoría pueda ser comprendida como un todo, cerrado, homogéneo, esencialista y, en consecuencia, sujeta a una finalidad última. Pero, si bien esto permite abrir las puertas a la pluralidad y las diferencias, cumpliendo con el compromiso ético a la base del feminismo, para poder hacer operativa la categoría mujeres como identidad política (aquella que ostentaría la agencia política, es decir, responsable del cambio social) se necesita volver a cerrar el concepto, es decir, hallar lo que hay de común y que permite (re)identificarnos y (re)situarnos dentro de las fronteras del concepto mujeres (o varones). Es decir, caer de nuevo en el problema de la exclusión. Como puede verse, parece que el problema se reduce, finalmente, a una cuestión de fronteras: quiénes podemos decir que están dentro y quiénes podemos decir que están fuera -entendiendo este podemos como una cuestión de derecho-.

\section{Las fronteras del género: Un paso hacia la agencia}

Y sobre fronteras habla Seyla Benhabib (2004) en su obra Los derechos de los otros. Extranjeros, residentes y ciudadanos. Aunque sus reflexiones se encaminan a examinar las fronteras de la comunidad política centrándose en la membresía política, es decir, sobre aquello que regula la condición de miembro de un determinado territorio, traslado aquí sus ideas para examinar las fronteras de la comunidad política las mujeres (identidad política a la que se dirigen las estrategias de lucha del feminismo) centrándome en la membresía del género.

Benhabib (2004) explica: "por membresía política quiero significar los principios y prácticas para la incorporación de forasteros y extranjeros, inmigrantes y recién venidos, refugiados y asilados, en entidades políticas existentes. Las fronteras políticas definen a algunos como miembros, a otros como extranjeros" (Benhabib, 2004, p. 13). Así como la Declaración de los Derechos Humanos (Naciones Unidas, 1948) reconoce el derecho a la libertad de movimiento a través de las fronteras de los países (el derecho a emigrar), las concepciones posmodernas sobre el género reconocen el derecho de movimiento a través de las fronteras del binarismo conceptual mujer-varón. De hecho, Benhabib ya deja entrever esta extrapolación teórica cuando reflexiona acerca de Jürgen Habermas y su construcción teórica de la acción comunicativa y la democracia deliberativa. 
Benhabib, consciente de la urgencia por ser de alguna manera que muestra la identidad, apuesta por aceptar la necesidad de que haya un sujeto, pero negándose a cerrar las fronteras con el fin de reconocer la pluralidad de modos de ser del ser humano y las diferencias entre las personas (sin considerar, a la vez, que esas pluralidades y diferencias son moral y políticamente válidas de antemano). Y para ello, entiende que es necesario reformular la concepción de sujeto teniendo en cuenta su radical situacionalidad y la marca de género que lo atraviesa, dado que tener en cuenta estos dos aspectos ayudará a no caer de nuevo en posturas extremas como el esencialismo o el relativismo. Es decir, pensar(nos) e identificar(nos) de tal modo que se puedan mantener las fronteras abiertas, evitando la exclusión. De este modo, formula su concepción del yo situado.

Ahora bien, se necesita un acuerdo o regulación (una serie de condiciones normativas, reciprocidad igualitaria, autoadscripción voluntaria y libertad para asociarse y para salir de la asociación) para que este ejercicio de reflexión se lleve a cabo de manera justa e igualitaria. Se debe atender a la obligación moral de justificar mis acciones con razones ante los otros individuos. Por tanto, se presuponen unos principios de respeto moral universal y reciprocidad igualitaria:

El respeto universal significa que reconocemos los derechos de todos los seres capaces
de habla y acción como participantes en la conversación moral; el principio de
reciprocidad igualitaria, interpretado dentro de los límites de la ética discursiva,
estipula que, en los discursos, cada uno debería tener los mismos derechos a varios
actos de habla e iniciar nuevos temas y reclamar la justificación de los presupuestos
de las conversaciones. (Benhabib, 2004, pp. 20-21)

Y a estos principios refiere Habermas (1983) cuando, como premisa básica de la ética discursiva, afirma que sólo son válidas aquellas normas y arreglos institucionales normativos que puedan ser coordenadas por todos los interesados bajo situaciones especiales de argumentación llamadas discursos.

Esto es considerado por Benhabib (2004) como una meta-norma, necesaria para incardinar y contextualizar las condiciones normativas y que supone asumir, así mismo, un universalismo moral en conjunción con un sentido político y legal. Lo cual no pude darse sin establecer una democracia deliberativa basada en la ética del discurso. A este respecto, la autora advierte que: "el discurso ético insiste en la necesaria disyunción, así como en la necesaria mediación entre lo moral y lo ético, lo moral y lo político. La tarea que le compete es de mediaciones, no de reducciones" (p. 22).

En relación con la identidad -política- de género, para cerrar el concepto haciéndolo operativo (concretamente, el concepto de mujeres para poder vehicular las demandas políticas del feminismo sin caer de nuevo en los errores del pasado), se ha de contemplar las situaciones concretas (históricas, legales y sociales) de cada individuo que se adscriba al mismo (reidentificándose y resituándose), resolviendo los conflictos (las diferencias entre dichos individuos adscritos al concepto mujeres) a través del diálogo. Al igual que sucede si se pretende resolver las diferencias en un mundo multicultural. No se trata de imponer quién/es han de considerarse e identificarse como mujeres (o varones), sino darles y darnos la oportunidad de reinterpretarnos a nosotras mismas, de hacernos partícipes del diálogo y, por tanto, no ser sólo receptoras de la historia sino, además, narradoras de la misma. Y es ahí donde se estaría dotando de agencia a los individuos.

Se observa que la capacidad de acción autónoma del individuo sólo es posible dentro de los confines de una comunidad solidaria que sostenga la identidad de cada una/o a través del reconocimiento mutuo. Por tanto, se está jugando, al mismo tiempo, entre las 
fronteras de una visión universal (la idea de mujeres en la que se congregan varios individuos) y las ataduras de lo particular (cada uno de esos individuos). Y Benhabib (2004) advierte que no es posible fundir lo moral universal en lo particular, lo legal o lo funcional. Por lo tanto, hay una brecha conceptual, la cual ha sido llenada por la ideología y las falacias naturalistas. Como se dijo anteriormente: no se puede acceder a la verdad sino a través de los discursos, las prácticas y normas.

Respecto a los Estados-Nación, Benhabib (2004) dice:

\begin{abstract}
Desde el siglo XIX y extendiéndose hasta las formaciones que emergieron luego de la descolonización y el fin del comunismo, esta «brecha conceptual» ha sido llenada por la ideología y práctica del nacionalismo. La ciudadanía y las prácticas de la membresía política son los rituales a través de los cuales se reproduce espacialmente la nación. El control de las fronteras territoriales, lo que es coexistente con la soberanía del Estado-Nación moderno, busca asegurar la pureza de la nación en el tiempo a través del control policial de sus contactos e interacciones en el espacio. (pp. 23-24)
\end{abstract}

El género y las prácticas de la membresía política de la identidad, son los rituales a través de los cuales se reproducen en la práctica las mujeres y los varones. Aquellas y aquellos que no reproducen en el tiempo fielmente estos mandatos, quienes no respetan la pureza del género, son castigadas/os y controladas/os a través de diversos dispositivos socioculturales, lográndose con ello regular sus contactos e interacciones en el espacio.

Siguiendo a Benhabib (2004), la estrategia a este respecto sería incorporar el derecho a ser narradoras y de adscribirnos libremente a un género, (equiparable al derecho de ciudadanía $^{6}$ ) a un régimen universal de derechos humanos. Es decir, desbancar la idea de referente fijo asociada al concepto mujer, la cual conlleva, repito, una normalidad que inmoviliza (que impide la agencia) abriendo el diálogo a las diferencias, esas que aún atrapadas bajo el paraguas del concepto mujeres se resisten a dejarse sobredeterminar. Pero esto no se puede hacer de manera arbitraria (que llevaría a un relativismo) -se necesita un acuerdo, un diálogo, para saber de qué, quiénes y para quiénes se está hablando-, sino que se basaría en una visión normativa, estimulada por un trasfondo que funciona como condición de posibilidad. Y esta visión normativa, que supone una regulación, para que no se pierdan de vista los principios de respeto moral universal y reciprocidad igualitaria, se ha de incorporar a una meta-norma, como se ha dicho, a un régimen universal de derechos humanos.

Benhabib (2004) observa respecto a la idea de soberanía de los Estados-Nación:

En las concepciones de soberanía liberal internacional, la igualdad formal de los estados depende de modo creciente de que suscriban valores comunes y principios tales como la observancia de derechos humanos y el dominio de la ley y el respeto a la autodeterminación democrática. La soberanía ya no significa autoridad última y arbitraria; se considera que los estados que violan ciertas normas en el trato a sus ciudadanos, que cierran sus fronteras, impiden un libre mercado, limitan la libertad de palabra y asociación y cosas por el estilo, no deben pertenecer a una asociación de

\footnotetext{
${ }^{6}$ Immanuel Kant indica en su obra "Sobre la paz perpetua" (1795) que el derecho de ciudadanía mundial debe limitarse a las condiciones de una universal hospitalidad, señalando lo extraño de la locución "hospitalidad" en este contexto, porque es una cuestión de derecho y no de filantropía. Benhabib comenta: "este «derecho» regula las interacciones de individuos que pertenecen a entes civiles diferentes pero que se encuentran el uno con el otro en los márgenes de comunidades circunscritas" (Benhabib, Los derechos de los otros. Extranjeros, residentes y ciudadanos., 2004, p. 30)
} 
estados específicas o alianzas; es crucial que los principios internos estén anclados en instituciones compartidas con otros. (Benhabib, 2004, p. 39)

\section{Consideraciones sobre la escuela inclusiva}

Volviendo a la relación de esta problemática con la escuela inclusiva, igual que supone algo positivo para el feminismo porque permite ir más allá a través de una reflexión crítica, considero que si trasladamos esta cuestión, y la forma de pensamiento que la acompaña, a las aulas, no sólo permitirá abrir la mirada para incluir las diferencias (podría pensarse en el colectivo LGTBI, pero también en nuevas concepciones como el BiGenero, el Gender Bender, Genderqueer...), para ayudarnos a comprender y enriquecernos con ellas, sino que además posibilitaría constituirnos desde el respeto. Este tipo de reflexiones y debates en el feminismo, si bien lejos de ofrecer conclusiones, aportan herramientas útiles para tratar de alcanzar una educación que favorezca el proceso de paz y elimine las tensiones, no sólo entre las diferentes culturas, sino además entre las diferentes formas de ser e identificarnos. Se trata de una cuestión de Justicia Social.

En el panorama actual, las reivindicaciones de Justicia Social han experimentado un desplazamiento, se ha trasladado el centro de gravedad de la política feminista, relacionándose más con la identidad y la representación que con la mera distribución.

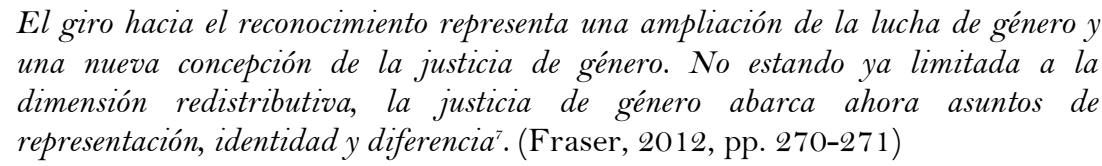

Nancy Fraser (2012), quien relega en su teoría el plano epistemológico en pro de lo político, observa que la lucha por el reconocimiento es fundamental. En el conflictivo panorama actual de la política, la lucha por el reconocimiento de la propia identidad de grupo (género, etnia, sexo...) son el motor de la movilización política. Hasta el punto que se ha subordinado la política de la redistribución a la política del reconocimiento. Ahora bien, Fraser (2012) advierte que esta lucha se desarrolla en un mundo desigualitario, no sólo socialmente, sino también materialmente, estando ambos aspectos estrechamente conectados. Además, señala que es necesario analizar y valorar qué diferencias merecen ser universalizadas y/o disfrutadas, lo que ayudaría al desarrollo de una política del reconocimiento en cuanto a tal, y no de la identidad. Y es que, al igual que Benhabib (2004), entiende que la política del reconocimiento se deberá a un proceso llevado a cabo mediante el diálogo cultural, poniéndose en cuestión ciertas pautas de representación, interpretación y comunicación, y dándose como consecuencia de ello, una aceptación y cambio en dichas pautas. De donde se desprende que el problema se halla estrechamente vinculado con la teoría del discurso ${ }^{8}$. Es necesario generar un sistema que

\footnotetext{
${ }^{7}$ Señalar que, si bien este es un aspecto positivo para Nancy Fraser, los logros más recientes del feminismo en el eje del reconocimiento habrían coincidido con un progreso estancado o un retroceso en el eje de la redistribución. Por ello, considera que es necesaria una concepción amplia del género capaz de acomodar, por lo menos, dos dimensiones analíticamente diferentes del sexismo: la que tiene que ver con la distribución y la que tiene que ver con el reconocimiento. El resultado será una concepción del género en dos dimensiones (Fraser, 2012).

${ }^{8}$ Fraser, coincidiendo con Butler y Benhabib, analiza el lenguaje en el plano de los discursos, a los que considera como prácticas sociales de comunicación históricamente específicas, vinculando, de este modo, el estudio del lenguaje al estudio de la sociedad. Propone un modelo pragmático del discurso, cuyas principales ventajas para el feminismo son: 1) considera a los discursos contingentes (el modelo se presta a la contextualización histórica y permite teorizar el cambio); 2 ) entiende la significación como una acción y no como representación, puesto que los sujetos hablantes son efectos de estructuras y
} 
permita pensar en las identidades sociales como complejas, cambiantes y construidas discursivamente.

\begin{abstract}
El reconocimiento señala una relación recíproca ideal entre personas, en la que cada uno contempla al otro como su igual y a su vez como separado de sí mismo. Esta relación se compone de la subjetividad: donde cada uno se convierte en ser individual sólo en la medida en que reconoce al otro sujeto y es reconocido por él. (Belavi y Murillo, 2016, p. 16)
\end{abstract}

Y esto es precisamente lo que defiende Benhabib (2004) al acuñar su concepción del yo situado. Reformulando la concepción de sujeto contextualizándolo, teniendo en cuenta su radical situacionalidad y la marca de género que lo atraviesa, es posible reconocer la pluralidad de modos de ser y las diferencias entre las personas. Siguiendo una ética discursiva habermasiana que incluya el género, se trata de una voluntad y disposición para buscar un entendimiento con el otro y llegar a algún acuerdo mediante una conversación de final abierto. Como se ha dicho, se hablaría de un universalismo interactivo, el cual "considera que la diferencia es un punto de partida para la reflexión y para la acción” (Benhabib y Cornella, 1990, p. 127), y en el que el yo situado se entiende como un yo interactivo-relacional. Se trata, precisamente, de admitir la dignidad del otro generalizado mediante el reconocimiento de la identidad moral del otro concreto (Portolés, 2009). Así mismo, haciendo alusión a estas reivindicaciones de las llamadas políticas del reconocimiento, Butler (2007) decía lo siguiente:

\begin{abstract}
Quizá ahora necesitamos una nueva política feminista para combatir las reificaciones mismas de género e identidad, que sostengan que la construcción variable de la identidad es un requisito metodológico y normativo, además de una meta política [...] Tal vez, paradójicamente se demuestre que la «representación» tendrá sentido para el feminismo únicamente cuando el sujeto de las «mujeres» no se dé por sentado en ningún aspecto. (p. 53)
\end{abstract}

Considero que la escuela, en tanto que debe favorecer la inserción de los individuos en la sociedad como adultos responsables y capaces de convivir con otros a pesar de las diferencias, es uno de los espacios principales donde poner en práctica este tipo de formulaciones. Es imprescindible para lograr asegurar unos cimientos sociales, una base, sobre la que comenzar a construir una sociedad equitativa, crítica y democrática. Es posible imaginar la escuela como un lugar donde desarrollar activamente la idea de hacernos, y hacer a las otras personas, partícipes del diálogo que nos configura como ciudadanos y ciudadanas, haciéndose a los individuos narradores activos, agentes, de una historia que, finalmente, deberán vivir conjuntamente. Y de la mano de este ejercicio conversacional de final abierto, es posible imaginar la apertura a las diferencias y multiplicidades de formas de ser y de identificarse.

Precisamente, con la antigua Ley Orgánica de Educación (2006), la atención a la diversidad suponía la superación de un modelo de educación instructivo y de transmisión para pasar a un modelo de superación y desarrollo, exigiendo en definitiva una escuela inclusiva abierta a la diversidad. Se formularon una serie de principios que buscaban el pleno desarrollo del alumnado, la educación en el respeto y las libertades fundamentales,

del sistema así como agentes situados en un contexto específico; 3) parte del supuesto de que en la sociedad existe una pluralidad de discursos diferentes, enfoque que ayuda a la elaboración de una teoría de las identidades sociales como no monolíticas; 4) rechaza el supuesto, por tanto, de que los significados sociales en circulación constituyen un "sistema simbólico único y coherente que se reproduce a sí mismo”, porque siempre hay conflictos entre los esquemas sociales de interpretación y los agentes que los ponen en circulación; 5) por último, vincula el estudio de los discursos con la sociedad, lo que permite atender a los problemas fundamentales del poder y la desigualdad. 
una educación para el ejercicio de la tolerancia y la libertad, y la formación en el respeto a la pluralidad. Y esta evolución en la consideración del modelo educativo no sería posible, repito, sin pensadoras y pensadores que lleven a cabo reflexiones como la desarrollada en el presente escrito.

\begin{abstract}
El concepto de integración escolar ha estado en el centro del debate educativo, presentándose con unos perfiles que han ido cambiando sucesivamente. En un principio, integración escolar quería decir, sobre todo, emplazamiento físico en el centro o en el aula ordinarios; posteriormente se entendió como inserción gradual, en la escuela ordinaria y en la sociedad, del alumnado con necesidades educativas especiales, finalmente se identifica con un proyecto global de centro pensado para educar en y para la diversidad. (Araque y Barrio, 2010, p. 10)
\end{abstract}

Frente a propuestas educativas actuales que pretenden dar una visión aparentemente ahistórica y natural, aplicándola tanto a los contenidos formativos como a las metodologías didácticas y a las formas de estructuración escolar, se desarrollan afortunadamente planteamientos críticos que tienen como criterio normativo ofrecer un rumbo político y cultural sobre la base de un compromiso ético. Suponen una propuesta y un responsabilizarse con nuevas formas de entender y enfocar la educación de la diversidad del alumnado sobre el horizonte de la idea de Justicia Social, que

desnaturalizan las injusticias para concebirlas como construcciones socio-históricas
contra las que luchar desde los centros escolares. Para ello, los y las docentes han de
retomar el trabajo intelectual como una destreza política y social que llevan consigo
para transformar las tradiciones dominantes. Al politizar la idea de enseñanza
desde una perspectiva transformadora que hace frente a "las normas prevalecientes y
a los regímenes establecidos de verdad" (McLaren, 1984, p. 293), se cuestionan las
costumbres y condiciones históricas que han impedido que las escuelas y los maestros
y maestras asuman su potencial de reflexión y acción social. (Pérez-Rueda et al.,
2016, pp. 5-6)

\title{
6. Conclusiones
}

En la actualidad, hay innumerables voces que abogan por una escuela inclusiva, se reclama alcanzar la igualdad social en el sistema educativo, estableciéndose como meta primordial la atención a las diversidades, procurando responder a las necesidades de todo el alumnado. Para que el sistema educativo pueda ser coherente con dichos principios y alcanzar las metas planteadas, opino que es igualmente importante considerar y reparar en el hecho de que, dentro de la multiplicidad y las diferencias, se haya el consabido binomio varones-mujeres en el que, a su vez, hay toda una gama de formas de ser e identificarse: bajo el paraguas de la categoría mujeres (o varones) se hayan atrapadas diversidades, pluralidades humanas que componen una sociedad de diferentes que impelan, también, a tomar conciencia de tener que aprender a convivir en el respeto a las diferencias.

Planteamientos actuales en el seno de la teoría crítica feminista pueden ayudar a considerar y enfocar el modo en cómo abordar esta problemática en el ámbito educativo, evitando con ello la segregación en las aulas y logrando una educación en la igualdad y en el respeto que instaure unos cimientos sociales sobre los que comenzar a construir una sociedad crítica, equitativa y democrática.

Así, la teoría de Judith Butler nos presta herramientas para reflexionar sobre la problemática del paradigma negativo de formación de la identidad. La política de la identidad, estrechamente relacionada con las políticas del reconocimiento, es deficiente 
porque "tiende a reificar la identidad femenina y a obscurecer los ejes transversales de subordinación. Como resultado, recicla los estereotipos de género dominantes y promueve el separatismo y lo políticamente correcto" (Fraser, 2012, p. 279). Butler ayuda a reconocer las condiciones normativas que se encuentran tras las narraciones discursivas a través de las cuales se conforman las identidades, afirmando que nada hay anterior al lenguaje y liberando el término mujeres para un futuro de múltiples significaciones. Lleva a una politización radical del sujeto, porque como ya se dijo: sin pensar en la politización del sujeto no es posible pensar en el sujeto para la política.

Se postula que el sujeto universal las mujeres no debería ser el fundamento de las exigencias políticas del feminismo, sino que la política feminista debería partir de una construcción variable de la identidad. Es decir, se reclama ahora una política noidentitaria, evitando con ello la asunción de patrones androcéntricos de valor cultural que impiden la paridad de género. No es posible representar por adelantado, dado que nada garantiza una unidad como resultado. Por su parte, Seyla Benhabib (2004), si bien de acuerdo con este planteamiento, previene de que no es posible deconstruir el término mujeres, esto es, abrir las fronteras del concepto, con el fin de hacerlo inclusivo, radicalizando la crítica hasta el extremo de que todo vale.

Critica la ambivalencia filosófica y política en este tipo de discursos acerca de la identidad de género -política-: se da una contradicción entre el derecho de todo ser humano a re-definir-se y re-situar-se en una categoría y la necesidad de soberanía, de autogobierno, de dicha categoría vista de un modo generalizado, es decir, su urgencia por ser de alguna manera. Existe una gran tensión entre la obligación moral de otorgar a todo ser humano la adscripción libre a una categoría como mujeres y la prerrogativa de no extender este derecho a una membresía que pueda suponer una homogeneidad radical. Si todas y todos somos ya lo mismo desde este punto de vista los conceptos como mujeres o varones pasarían a suponer tautologías, porque serían una repetición innecesaria de un mismo pensamiento y, por tanto, no se avanzaría, no se aportaría ninguna información. Y esto negaría, igualmente, la posibilidad de operatividad al concepto mujeres tan necesario para articular las luchas políticas del feminismo. Esta es la problemática a la que se enfrenta la política feminista, que busca una identidad colectiva responsable del cambio social. Pero esta política no sólo atañe al género, "también puede aplicarse a otros ejes de subordinación como la «raza», la sexualidad, la etnicidad, la nacionalidad y la religión” (Fraser, 2012, p. 281).

Las reflexiones de Benhabib acerca de lo que aquí se ha llamado la membresía del género, aquello que regula la condición de miembro dentro de las fronteras de la comunidad política las mujeres, entraña un planteamiento de lo más interesante para el panorama político actual y, por extensión, para el ámbito educativo como responsable de la formación de individuos capaces de vivir en sociedad, a pasar de las diferencias, como adultos responsables. Supone una ampliación de la idea de escuela inclusiva, no sólo porque sitúa en el centro del debate psicopedagógico el hecho de que existen múltiples formas de ser y de identificarse que deben ser respetadas. Sino porque, además, brinda una nueva manera de pensar(nos) e identificar(nos) manteniendo, a su vez, las fronteras abiertas y evitando con ello la exclusión. Se propone resolver los conflictos -que son siempre inevitables- a través del diálogo. Nuestra agencia es la capacidad de establecer vínculos, de articular, de participar junto con otras y otros, esto es, de ser con otras/os y de hacer-nos con otras/os. Resultando este planteamiento, en mi opinión, sumamente enriquecedor a la hora de plantearnos una educación para el futuro. 


\section{Referencias}

Araque, N. y Barrio, J. L. (2010). Atención a la diversidad y desarrollo de procesos educativos inclusivos. Prisma Social, 4, 1-37.

Beauvoir, S. D. (2005). El segundo sexo. Madrid: Cátedra.

Belavi, G. y Murillo, F. (2016). Educación, democracia y justicia social. Revista Internacional de Educación para la Justicia Social (RIEJS), 5(1), 13-34.

Benhabib, S. (2004). Los derechos de los otros. Extranjeros, residentes y ciudadanos. Cambridge: Cambridge University Press.

Benhabib, S. y Cornella, D. (1990). Teoría feminista y teoría crítica. Valencia: Artes Gráficas Soler.

Benhabib, S. y Vassallo, A. (2006). Las reivindicaciones de la cultura: Igualdad y diversidad en la era global. Buenos Aires: Katz.

Bosch, E. A., Ferrer, V. y Alzamor, A. (2006). El laberinto patriarcal. Reflexiones teórico-prácticas sobre la violencia contra las mujeres. Barcelona: Anthropos.

Butler, J. (2007). El género en disputa. El feminismo y la subversión de la identidad. Barcelona: Paidós.

Castellanos, G. (2006). Sexo, género y feminismo: Tres categorías en pugna. Cali: Centro de Estudios de Género, Mujer y Sociedad.

Castro, C. (2015). Feminismo como crítica: Sujeto y universalidad. Oxímora: Revista Internacional de Ética y Política, 7, 202-213.

Derrida, J. (1998). Firma, acontecimiento, contexto. Madrid: Cátedra.

Foucault, M. (1979). Microfísica del poder. Madrid: Las Ediciones de las Piqueta.

Foucault, M. (2008). Un diálogo sobre el poder y otras conversaciones. Madrid: Alianza Editorial.

Foucault, M. (2012). Vigilar y castigar: Nacimiento de la prisión. Barcelona: Biblioteca Nueva.

Fraser, N. (2011). Redistribución, reconocimiento y participación. Hacia una concepción integrada de la justicia. En M. A. Carbonero Gamundí y J. Valdivielso (Coords.), Dilemas de la justicia en el siglo XXI: Género y globalización (pp. 291-308). Palma de Mallorca: Ediciones UIB.

Fraser, N. (2012). La justicia mundial y la renovación de la tradición de la teoría crítica. En A. Giorgio, J. Rancière y A. Badiou (Coords.), Pensar desde la izquierda: Mapa del pensamiento crítico para un tiempo en crisis (pp. 259-280). Madrid: Errata Naturae.

Galtung, J. (2003). Paz por medios pacíficos: Paz y conflicto, desarrollo y civilización. Bilbao: Bakeaz.

Gil, S. L. (2014). Ontología de la precariedad en Judith Butler. Repensar la vida en común. Éndoxa, 34, 287-302.

González-García, E. (2009). Evolución de la educación especial: Del modelo del déficit al modelo de la escuela inclusiva. En M. R. Berruezo y S. Conejero (Coords.), El largo camino hacia una educación inclusiva: La educación especial y social del siglo XIX a nuestros días (pp. 429440). Pamplona: Universidad Pública de Navarra.

Habermas, J. (1983). Conciencia moral y acción comunicativa. Boston, MA: MIT Press.

Lázaro, A. V. (2013). El sujeto político y la transformación social en Judith Butler y Seyla Benhabib. Bajo Palabra, 8, 275-282. 
Ley Orgánica 2/2006, de 3 de mayo, de Educación. Boletín Oficial del Estado, núm. 106, de 4 de mayo de 2006, pp. 17158-17207. Recuperado de https://www.boe.es/buscar/doc.php?id=BOE-A-2006-7899

Ley Orgánica 8/2013, de 9 de diciembre, para la mejora de la calidad educativa. Boletín Oficial del Estado, núm. 295, de 10 de diciembre, pp. 97858-97921. Recuperado de https://www.boe.es/boe/dias/2013/12/10/pdfs/BOE-A-2013-12886.pdf

Martínez-Abellán, R., de Haro, R. y Escarbajal, A. (2010). Una aproximación a la educación inclusiva en España. Revista Educación Inclusiva, 3(1), 149-164.

Pérez-Rueda, A. I., Méndez-Núñez, A., Suavita, M., Moreno-Medina, I., y Belavi, G. (2016). Hacia una formación crítica del profesorado. Revista Internacional de Educación para la Justicia Social (RIEJS), 5(2), 5-11.

Portolés, A. O. (2009). La pregunta por el sujeto en la teoría feminista. El debate filosófico actual. Madrid: UCM Ediciones.

Rubin, G. (1986). El tráfico de mujeres: Notas sobre la "economía política" del sexo. Nueva Antropología, 30, 95-145.

UNESCO. (1990). Declaración mundial sobre educación para todos y marco de acción para satisfacer las necesidades básicas de aprendizaje. Nueva York, NY: UNESCO.

UNESCO. (1994). Conferencia mundial sobre necesidades educativas especiales: acceso y calidad. Madrid: Ministerio de Educación y Ciencia

Ventura, A. (2016). Género, identidad y performatividad en Judith Butler. Santa Cruz de Tenerife: Universidad de La Laguna.

Wellmer, A. (1993). Sobre la dialéctica de modernidad y postmodernidad. La crítica de la razón después de Adorno. Madrid: Visor Distribuciones.

\section{Breve CV de la autora}

Licenciada en Filosofía (2013) por la Universidad Autónoma de Madrid. Máster en Estudios Interdisciplinares de Género (2014) por el Instituto Universitario de Estudios de la Mujer (UAM). Trabajo final de máster: "La violencia contra las mujeres ejercida en la pareja: reflexiones desde un enfoque epistemológico". CFGS en Integración Social (2017) por el Instituto Francesc Ribalta, Castellón de la Plana. Realiza actualmente el doctorado en Estudios Interdisciplinares de Género del Instituto Universitario de Estudios de la Mujer en la UAM, en la línea de investigación: "Teorías Feministas, ciudadanía y globalización". Tesis titulada "Agencia e identidades: nuevas concepciones feministas para repensar la política”. ORCID ID: 0000-0003-1116-2542. Email: palomacurieses@gmail.com 